\title{
Elite Cues and Economic Policy Attitudes: The Mediating Role of Economic Hardship
}

\author{
Charlotte Cavaillé $^{1} \cdot$ Anja Neundorf ${ }^{2}$ iD
}

Accepted: 23 December 2021

(c) The Author(s) 2022

\begin{abstract}
Do voters update their attitudes toward economic issues in line with their material self-interest? The consensus among students of public opinion is that material selfinterest plays a very limited role and that competing non-material factors, such as partisanship or ideological predispositions, do most of the heavy lifting. This paper moves beyond comparing the role of material and non-material factors. Instead, we examine how these factors combine to shape policy preferences. Specifically, we propose a friendly amendment to Zaller's influential model according to which attitudinal change results from the interaction between changes in elite messaging on the one hand and individual political predispositions on the other. In Zaller's model, partisanship and ideological predispositions help explain why some resist and others embrace new elite messaging. We hypothesize that material self-interest also conditions the effect of elite messaging. Using British individual-level panel data collected over more than a decade, we show that material hardship predicts who, among left-wing voters, resist new right-wing partisan cues. Our results highlights the incremental impact of material self-interest on economic attitudes.
\end{abstract}

Keywords Attitude formation · Economic preferences $\cdot$ Self-interest $\cdot$ Panel data $\cdot$ Great Britain · Zaller

\footnotetext{
An earlier version of the paper was presented at the Annual Conferences of MPSA (Chicago, April 10-14, 2013). We are grateful to participants of Harvard Political Economy (special thanks to Jim Alt), Harvard American Politics and Harvard Political Psychology workshops, the Joint Empirical Social Sciences (JESS) seminar at the Institute of Social and Economic Research at the University of Essex, the Research Forum Political and Social Science at Universitat Pompeu Fabra, the Political Economy seminar at the Moscow Higher School of Economics, the Nuffield Politics Seminar, University of Oxford in particular for taking the time to comment on an earlier drafts of this paper. We would also like to acknowledge generous funding from the Carnegie's Bridging the Gap grant, as well as funding from Georgetown University's School of Foreign Service Summer Grant.
}

Anja Neundorf

anja.neundorf@glasgow.ac.uk

Extended author information available on the last page of the article 
How do people form opinions on economic and redistributive policies? How do these opinions change? One framework, common among studies of American public opinion, emphasizes the interaction between the political context, as shaped by political elites competing for power, and individual characteristics such as political ideology or party identification. According to this line of work, opinion change is more likely "when partisan elites debate" and disagree over "an issue and the news media cover it" (Dancey \& Goren, 2010, p. 686). People exposed to elite-level debates and disagreements will embrace some claims and resist others depending on the political family they identify with (Leeper \& Slothuus, 2014; Zaller, 2013). We extend this argument further and hypothesize that a person's economic conditions constitute another mediating factor.

To test this argument, we turn to a unique British panel dataset with repeated measures of both economic hardship and attitudes toward economic and redistributive issues. ${ }^{1}$ The data was collected in the period preceding and following Tony Blair's successful 1997 election bid. During this period, the Labour Party moved toward the Conservative Party's positions on economic issues, describing market mechanisms in more positive terms and dropping income redistribution from its stated policy goals (Fielding, 2003; Milazzo et al., 2012). According to John Zaller's model of preference formation and change, such shift in party messaging has implications for how people answer survey questions about economic issues. Specifically, given that the Labour Party's messaging shifted from left-wing statements to a mix of right-wing and centrist ones, we should observe a portion of Labour sympathizers with left-wing attitudes "follow the leader" (Lenz, 2013) and become more ambivalent with regards to left-wing economic policies. But who will be most likely to embrace elite rhetoric and update their survey responses? Who, in contrast, will resist party cues and not change how they answer items on economic issues? We argue that individual economic factors help explain who is most likely to embrace or resist changes in elite messaging. One reason is issue importance: people experiencing economic hardship are more likely to care about economic issues and, as a result, more likely to resist elite messaging. A second reason is the extent to which elite messaging resonates with one's own experience: we expect people experiencing economic hardships to be more likely, relative to individuals experiencing no hardship, to resist dissonant right-wing considerations about the economy and embrace consonant left-wing ones.

To examine these expectations, we rely on a measurement model that classifies respondents based on their response pattern to a set of six survey items. To examine the effect of hardship, we model attitudinal change as a first-order Markov chain and examine how changes in a respondent's material conditions affect the probability of transitioning from a consistently left-wing response pattern to a more ambivalentcentrist one. Within our sample, we document an increase in the share of respondents categorized as ambivalent-centrist on economic issues. This shift is due to individuals who entered the panel with consistently left-wing response patters and

\footnotetext{
1 Throughout the text, we use the expressions "economic preferences" and "attitudes on economic issues" interchangeably.
} 
appear to "follow" the New Labour's right-wing messaging shift. Most importantly, we show that material hardship affects who follows and who resists.

Our friendly amendment to public opinion scholars' workhorse model both builds on and speaks to extensive cross-sectional evidence that economic attitudes vary with economic circumstances, whether captured by class, education or income (Cavaille \& Trump, 2015; Chan \& Goldthorpe, 2007; Langsæther \& Evans, 2020). While this relationship is well documented, its interpretation is far from consensual. For some scholars, people who occupy different class and income positions have different economic attitudes because they have different economic interests (Brooks \& Svallfors, 2010; Chan \& Goldthorpe, 2007). Other scholars who focus on the causal effect of material circumstances on economic attitudes disagree with this interpretation, which they argue, is inconsistent with evidence that economic shocks have only small and transient effects on attitudes (Margalit, 2019). As we discuss in the conclusion, our argument offers a way to model the effect of material self-interest that is consistent with both lines of reasoning. Furthermore, it suggests that the cross-sectional correlation between economic position and attitudes emerges from the combined effect of exposure to interest-congruent messaging and resistance to interest-incongruent messaging.

\section{Self-interest and Preference Formation}

Many scholars, especially students of American public opinion, argue that attitude formation and change have little to do with material self-interest and much more to do with non-economic modes of reasoning such as value-based or partisan-motivated reasoning (Margalit, 2013; Sears \& Funk, 1990). This conclusion is rooted in studies designed to assess material self-interest's explanatory power relative to other modes of reasoning. ${ }^{2}$ In the next section, we answer a different question: how might self-interest and alternative modes of reasoning interact and combine to affect attitude formation and change?

\section{A Simple Addendum to Zaller's Theory of the Survey Response}

To answer this question, we start from Zaller and Feldman's theory of the survey response, which underpins the majority of studies on opinion formation and change. According to (Zaller \& Feldman, 1992, p. 79), "most citizens do not possess preformed attitudes at the level of specificity demanded in surveys." Rather, they carry around in their heads "a mix of only partially consistent ideas and considerations." Individuals express an opinion by reaching into their own "basket" of existing considerations about an issue. Which consideration ends up being sampled is a function of the types of considerations that are cognitively easier to retrieve. This simple framework suggests two main reasons why survey responses might change over

\footnotetext{
${ }^{2}$ See Chong et al. (2001) for an exception.
} 
time. One has to with the heterogeneity of one's basket of considerations (or ambivalence). Assuming enough heterogeneity, over-time variation follows from respondents sampling a different consideration each time the same survey question is asked. Variation might also result from a change in the mix of considerations individuals hold on a given issue. Accordingly, a left-wing (right-wing) shift in response patterns on economic issues follows from both an increase in the likelihood that individuals with "mixed" baskets sample left-wing (right-wing) considerations and an increase in the share of individuals whose basket includes mostly left-wing (rightwing) considerations. Empirically, researchers only observe a change in a single survey answer and can rarely distinguish between the two types of attitudinal change. Yet one is more durable than the other, something we come back to when discussing our empirical strategy.

According to Zaller (1992), a key trigger of mass attitudinal change, as captured using common survey methodology, is a change in elite rhetoric. First, in the process of building electoral coalitions, political elites competing for political power change the nature and range of perspectives and arguments available in voters' discursive context. In other words, political elites are important first movers: their behavior affects issue salience — what is being discussed — and issue framing - how it is being discussed-, shaping the considerations likely to be on top of a respondent's mind, and ultimately generating coordinated patterns of attitudinal change large enough to be captured in mass surveys. Second, by altering the range of policy considerations available to citizens, political elites also provide conditions conducive to more durable attitudinal change: they increase the likelihood that people will be exposed to new political messaging, ultimately incorporating new considerations and altering the mix of considerations from which people sample.

According to Zaller (1992, p. 44), “(p)eople tend to resist arguments that are inconsistent with their political predispositions." Predispositions, are, to simplify, selection mechanisms that shape acceptance or rejection of elite messaging. Zaller, and scholars building on his synthetic model, distinguish between at least two types of selection mechanisms. One mechanism is the (mis)match between elite messaging and the considerations already available in an individual's existing basket: the more homogeneous the existing basket, the less likely the acceptance of an argument that runs counter to it. We call this type of selection mechanism "predispositional consistency." The second type of mechanisms are cognitive short-cuts that individuals rely on to chose whether or not to accept a given argument or claim. One well studied short-cut is the partisan heuristic, which makes people more likely to accept (reject) arguments and claims that they associate with the political party they identify with (oppose).

To this well-known list of mediating mechanisms, we add material self-interest. ${ }^{3}$ To understand how material self-interest mediates the effects of a change in

\footnotetext{
3 Zaller's model, developed in the 1990s, does not mention material circumstances, overlooking the robust cross-sectional relationship between economic position and attitudes (see Langsæther and Evans (2020) for review). This relationship makes material self-interest an obvious candidate as a mediating mechanism.
} 
elite messaging on individual attitudes, we draw on findings in social psychology. As originally documented by Krosnick et al. (1993), policy attitudes on issues that "directly affect (a person's) rights, privileges, or lifestyle in some concrete manner" (Howe \& Krosnick, 2017, p. 328) are more "important" than policy attitudes on issues that have no direct personal implications. Because left-wing economic policies have direct and concrete implications for people experiencing hardship, we expect attitudes towards such policies to be more important to people experiencing economic hardship than to people not experiencing such hardship. According to Boninger et al. (1995), resistance to elite messaging is much higher for important attitudes relative to non-important attitudes. For example, as shown by Carsey and Layman (2006) and Dancey and Goren (2010) in the case of abortion, people who say that this issue is important to them resist embracing the party's new policy position if it conflicts with their own (see also Zaller, 2013). Building on these findings, we expect people experiencing economic hardship to be more likely to resist rightwing elite messaging, especially if it conflicts with their existing left-wing attitudes.

A related mechanism is people's tendency to prefer self-serving considerations over others (Sears \& Funk, 1991). Given competing considerations about the state of the world, individuals tend to prefer considerations that resonate with their own experience and help maintain their own self-esteem (DeScioli \& Kurzban, 2009). In this paper, we examine the case of economic considerations, an issue area for which there is ample evidence of egocentric bias. Indeed, as most recently shown by Hvidberg et al. (2020), beliefs about the fairness of the income distribution and economic institutions are correlated with socio-economic status: economic "losers" are less likely than economic "winners" to believe that effort pays and that resources are fairly distributed (see Montada, 1998 for a review). As shown by Marshall (2016) using a plausibly exogenous variation in education-level and income, at least part of this relationship is causal. As a result, if people are exposed to a range of leftwing and right-wing considerations on economic issues, we expect people experiencing hardship to be more likely to accept left-wing consonant considerations and resist right-wing dissonant ones. If people are mostly exposed to right-wing considerations, hardship's main effect will be one of resistance to right-wing dissonant considerations.

\section{The British Case}

To test our argument regarding the mediating role of material self-interest, we turn to high-quality panel data collected in Great Britain during a period of significant shifts in elite discourse on economic issues. The transformation of the British party system is well documented and has attracted much attention from political commentators and scholars. Figure 1 documents changes in the Labour and the Conservative Parties' electoral manifestos (see Appendix 1.1 for details on the measures). In the early 1980s, close to a third of the two parties' manifestos were dedicated to economic issues (right panel). In reaction to Thatcher's shift to the right on economic issues, the Labour Party leaders initiated a turn to the left, "widely thought to have been the most (radical) in the party's history" (Fielding, 2003, p. 25). However, 


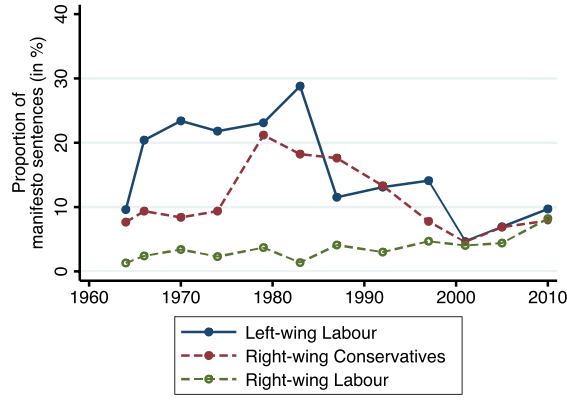

(a) Economic issues: directionality

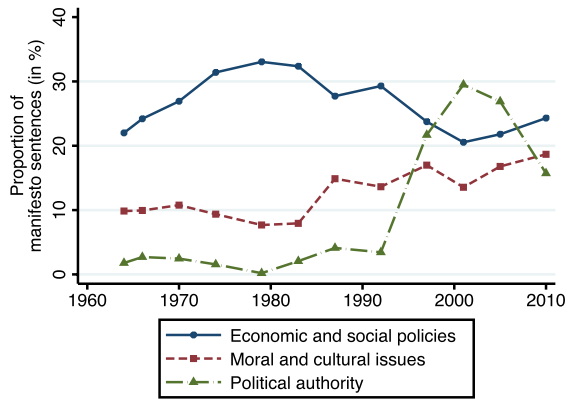

(b) Economic issues: relative salience

Fig. 1 Changes in party manifestos: 1960-2011 Left panel plots the share of sentences addressing economic issues and coded as left-wing or right-wing, broken down by party. Right panel plots the share of sentences addressing economic and non-economic issues, irrespective of right-wing or left-wing directionality and with both parties' manifestos considered jointly. Source The Manifesto Data Collection, (Volkens et al., 2013)

from the mid-1980s onwards, both parties started moderating their positions (left panel). In this paper, we focus on one important episode in this convergence process, namely Tony Blair's control of the Labour Party during the 1990s and 2000s. As party leader from 1994 to 2007 and Prime Minister from 1997 to 2007, Blair famously altered the party's platform and messaging, "advocating for lower taxes and reduced welfare dependency (...) fiscal prudence, and personal responsibility" (Milazzo et al., 2012, p. 265). In a telling analysis of House of Parliament speeches, O'Grady (2021) documents the steady decline in the utterance of the word "redistribution," with "the lowest use recorded on the eve of the (2008) financial crisis." While the word "redistribution" was on the decline, references to "work, reform and fraud" were, starting in the early 1990s, on the rise. O'Grady shows that this increase was due to a change in Labour MPs' rhetoric. This right-wing shift was accompanied by a more general decline in ideological cues: notice in Fig. 1 (right panel) the sharp rise in non-ideological references to party and leader competence (the "political authority" category).

As we document in Appendix 1.2, this change in elite rhetoric was relayed in the media. Specifically, the prevalence of left-wing economic and redistributive considerations found in the media decreased over this period. As documented in Appendix 1.3 , the electorate was very much aware of this shift in party and media discourse. Jeremy Corbyn, elected as party leader in 2016, represents a striking reversal of this trend. Unfortunately, because our dataset stops in 2007, we cannot examine how this change in leadership, and its effect on the discursive context, have affected mass attitudes.

Using the model sketched earlier, we examine how a change in elite rhetoric on economic issues shapes attitudes as measured using common survey methodology. Overall, the discursive context in Great Britain during this period is not conducive to an increase in left-wing economic attitudes. Indeed, this convergence's main consequence is a decrease in the number of traditional left-wing policy considerations 
available in the political debate and an increase in centrist and right-wing ones associated with the Labour Party. From the perspective of individual voters, this has three implications. First, individuals with a mixed basket of considerations become less likely to have left-wing consideration on the top of their mind. Second, fewer individuals are exposed to new left-wing considerations. Finally, more individuals are exposed to right-wing considerations. The change is especially significant for individuals who start the period identifying with the Labour Party: their exposure to left-wing frames and considerations coming from Labour elites declines while their exposure to right-wing frames and considerations coming from Labour elites increases.

As a result, we expect a decrease in the share of individuals who appear left-wing on redistributive and economic issues. This change should be especially important among Labour sympathizers who pay attention to politics and thus notice the change in elite cues. Given that attitudes are more likely to change around major upswings in the discursive context, we focus on 1997, the year the Labour Party ran for office on its "New Labour" platform. More specifically, we examine the following prediction:

Prediction 1 Individuals' attitudes on economic issues exhibit a right-wing shift starting in 1997. The shift is larger among individuals who pay attention to politics and who, at the beginning of the panel, feel closer to the Labour Party.

As we discuss in the empirical section, among people classified as left-wing by our measurement model, only 1 in 10 feel close to the Conservative Party, while 8 in 10 feel closer to the Labour Party and 1 in 10 do not identify with any of the two main parties. This implies that people with left-wing economic preferences are cross-pressured. Because many are Labour sympathizers, reliance on the partisan heuristic encourages them to respond to right-wing cues by changing their survey responses. However, given their existing left-wing issue position, predispositional consistency pushes them to resist. To predict how cross-pressured individuals will behave, we turn to material self-interest:

Prediction 2 Among people with left-wing attitudes on economic issues, those who have experienced a negative economic shock are more likely to resist party cues and consequently less likely to experience a right-wing shift in attitudinal response patterns.

Prediction 1 is commonly found in studies of public opinion that implicitly or explicitly build on Zaller's model. Prediction 2 tests our friendly amendment to this model, focusing on a subset of voters for which workhorse models produce contradictory expectations. Both predictions assume that the platform and discursive changes leveraged in this paper are exogenous to attitudinal change among the British public in general and Labour sympathizers in particular. ${ }^{4}$ As documented in Appendix 1.4, changes in party platform were not preceded by a right-wing shift in mass economic attitudes. These changes were partly a response to past electoral

\footnotetext{
4 As discussed above, this assumption is constitutive of the field of research-public opinion and survey research - on which we build; lack of space prevents us from a full review of supporting evidence (e.g., Evans \& Tilley, 2012; Lenz, 2013; Zaller, 1992, 2013).
} 
losses, which gave what Rodden (2019) calls the "suburban pragmatists" an advantage over "urban ideologues" for control of the party. These losses where themselves due to factors beyond elites' control including the decline of the traditional industrial working class, the failure of Keynesian demand management and the search for a new policy paradigm to address this failure (Hall 1993). Note that none of these factors assume a change in mass preferences. Ultimately, our focus on individual-level dynamics and estimates, not aggregate-level ones, minimizes the risk of reverse causality: elite discourse is more likely to influence a given individual's own preferences than the other way around. ${ }^{5}$

\section{Empirics}

To test predictions 1 and 2, we turn to the British Household Panel Survey (BHPS). ${ }^{6}$ The BHPS is an annual survey that provides high-quality socio-economic data at the individual and household level. It consists of a nationally representative sample of about 5500 households recruited in $1991 .^{7}$ Given the emphasis in prediction 2 on changing economic conditions, we restrict our sample to the working-age population (16-65) excluding retirees and respondents in full-time education from the analysis: for these groups, income shocks are more difficult to measure. For institutional and historical reasons, devolved regions have developed distinct party systems built around separate political cleavages. In Scotland for example, economically left-wing voters split their vote between the Labour party and the Scottish National Party. These differences imply very distinct discursive contexts and partisan cues. As a result, we drop all devolved regions from our analysis and focus on respondents living in England. We further select individuals with valid responses on our measurement items for at least three time periods, yielding a total of 5745 observations. $^{8}$

\section{Variables and Empirical Strategy}

\section{Measurement of Attitudes on Economic Issues}

The BHPS includes a number of attitudinal questions. Six of these items tap into support for, or opposition to, traditional left-wing economic and social policy preferences. They were measured on seven occasions between 1991 and 2007. We have

\footnotetext{
${ }^{5}$ People who hold consistently left-wing economic policy preferences might prefer to leave the Labour Party and switch to a party to the left of Labour. Yet, in this particular case, left-wing voters have no party to switch to as the electoral rule precludes the emergence of a party to the left of Labour. One implication is an increase in abstention (see Heath, 2018 for a discussion).

${ }^{6}$ Replication materials and code can be found at Neundorf and Cavaille (2021).

${ }^{7}$ For more information about the BHPS, visit https://www.iser.essex.ac.uk/bhps.

${ }^{8}$ We restrict the estimation to respondents with at least three valid responses, as this provides at least two changes in economic policy preferences per respondent. For more information, see Neundorf et al. (2011).
} 
re-coded them such that higher values indicate a more right-wing answer. Respondents were asked whether they agreed or disagreed with the following statements:

1. Ordinary people share nation's wealth

2. There is one law for the rich one for the poor

3. Private enterprise solves economic problems

4. Public services ought to be state owned

5. Government has an obligation to provide jobs

6. Strong trade unions protect employees

These items are interesting because they directly ask about 'old' Labour issues, i.e., conflict between management and labor, disagreement over the fairness of market economies, and governments intervention to help the "little guy." This is precisely the world view that New Labour dropped from its political platform starting in the mid-1990s. With Tony Blair's arrival to power, party messaging moved in a rightwing direction: his government introduced public-private partnerships for public services, communicated that the Labour Party was also the party of the successful entrepreneurs, and implemented workfare reforms designed to push unemployed workers off the "dole."

Based on answers at each measurement occasion, we estimate a latent class model, which defines a segmentation into $N$ discrete classes, under the assumption that individuals' patterns of answers to the 6 items are driven by their class membership. Comparing the model fit between models with 1 up to 5 classes, we settle on $N=3$. $^{9}$ One class is constituted of individuals who answer the six survey items in a consistently left-wing fashion. The second one is constituted of individuals who answer in a consistently right-wing fashion. Finally, a third category is constituted of individuals who do not appear to be committed to one policy position over the other. We describe this class of individuals as ambivalent-centrists, with an emphasis on "ambivalent." Indeed, as documented by Broockman (2016), many survey respondents who give a mix of left and right-wing responses are often best described as conflicted or ambivalent, not necessarily as moderate centrists.

Our aim is to measure the effect of elite cues and hardship on attitudinal stability and change. As discussed on page 4, when studying change in answers to a single survey item, it is difficult to distinguish between durable change (i.e., change in the set of considerations people sample from) and temporary change (i.e., a change in the particular considerations that happen to be "on top" of individuals' mind at a given point in time). Using a multi-item approach, researchers can minimize measurement error introduced by the latter. By relying on a categorical multiitem approach, we are choosing to emphasize qualitative differences in patterns of answers (e.g., consistent versus ambivalent) under the assumption that switching from one latent class to another is - given the qualitative change-both meaningful

\footnotetext{
9 As Appendix 2.1 confirms, model fit greatly improves if we hypothesize the existence of three different classes, and only marginally improves when we fit models for which $N>3$. All estimates from the latent class measurement model are shown in Appendix 2.2.
} 
and durable. Furthermore, we are interested in these qualitative differences because, combined with the first-order Markov transition process described below, they allow us to better identify the specific impact of hardship on attitudinal stability, net of other mechanisms of attitudinal persistence (e.g., lack of exposure to elite cues) and resistance (e.g., predispositional consistency), something we come back to after having presented the model in full.

\section{Modeling Within-Person Dynamics of Latent Attitudes}

We use a first-order Markov transitioning structure, where the state at time $t$ is a function of the state at time $t-1$. Such a latent Markov model is specified as:

$$
P\left(y_{i t} \mid x_{i 0}\right)=\sum_{\theta_{0}=1}^{T} \cdots \sum_{\theta_{T}=1}^{T} P\left(\theta_{0} \mid x_{i 0}\right) \sum_{t=1}^{T} P\left(\theta_{t} \mid \theta_{t-1}\right) \sum_{t=1}^{T} P\left(y_{i t} \mid \theta_{t}\right),
$$

This model specifies the categorical level variable measuring latent economic attitudes $\theta_{t}$, to be a function of previously held latent attitudes $\theta_{t-1}$ and a level of measurement error that and is assumed to be time invariant for reasons of identification. Note that model 1 includes covariates $x_{i 0}$ on the initial state of economic policy preferences $\theta_{0}$, when respondents first entered the panel. These account for observed characteristics that predict the probability that a respondent has economically left or right-wing preferences in the first place. The coefficients are reported in Appendix 2.3.

The model's transition dynamics are parametrized by a multinomial logit model, which estimates the probability of being in state $r$ instead of $s$-being for instance classified as left-wing instead of an ambivalent-centrist-as a function of overall intercepts and time effects. The $\beta$ coefficients are set to zero for $r=s$.

$$
\log \left[\frac{P\left(\theta_{t}=r \mid \theta_{t-1}=s\right)}{P\left(\theta_{t}=s \mid \theta_{t-1}=s\right)}\right]=\beta_{0 r s}+\beta_{1 r s t} \text { time }_{i t}
$$

These specifications yield a time-heterogeneous Markov transition structure in which transition probabilities in-and-out of the latent classes of policy preferences differ between survey waves, allowing us to examine the temporal fit between documented changes in the discursive context and preference change (or stability) from one wave to the next.

\section{Partisanship and Political Interest}

To test prediction 1, we further need to distinguish between people more (less) likely to "follow" Labour rhetoric because they identify (do not identify) with the Labour party. At each wave, respondents were asked which party they feel closest to. Using only data collected before 1997, we code as Labour sympathizers people who report feeling closer to the Labour Party at least once (40\%). We do the same with people who feel closer to the Conservative Party (36\%). Note that the share of people reporting feeling closer to the Labour party one wave and close to the Conservative 
party another is negligible (less than 5\%). To measure exposure to elite messaging, we follow common practices and use a survey item asking respondents whether or not they are interested in politics. Given that political interest is very stable over the life-cycle (Prior, 2010), we use the average level of reported political interest across all available panel waves. This average score classifies respondents as high (above median) and low interest in politics (below median).

According to prediction 1, transition patterns should differ depending on degrees of exposure and partisanship. We therefore estimate the following model separately for respondents with high and low political interest, ${ }^{10}$ where transition probabilities are conditioned on partisanship:

$$
\log \left[\frac{P\left(\theta_{t}=r \mid \theta_{t-1}=s\right)}{P\left(\theta_{t}=s \mid \theta_{t-1}=s\right)}\right]=\beta_{0 r s}+\beta_{1 r s t} \text { time }_{i t} \mid \text { partisanship }
$$

\section{Material Conditions}

To test prediction 2, we introduce covariates $w_{i t}$ that measure changes in a respondent's material conditions. We introduce these variables as predictors of the transition probability of preference updating by extending model 2 as follow:

$$
\log \left[\frac{P\left(\theta_{t}=r \mid \theta_{t-1}=s\right)}{P\left(\theta_{t}=s \mid \theta_{t-1}=s\right)}\right]=\beta_{0 r s}+\beta_{1 r s t} \mathrm{time}_{i t}+\beta_{r s} w_{i t}
$$

In order to measure changes in material hardship (whether positive or negative), we use two sets of variables. First, we include substantial changes in a respondent's labor income (increase or drop of at least 25\%) and changes in employment status (loosing or finding a job) as measures of objective hardship (Margalit, 2013). Note that, for some respondents, these shocks might have been anticipated. To the extent that hardship is measured with error, the estimates on objective measures will be biased downward. As a result, we also rely on subjective measures of individual economic conditions, specifically reported job insecurity and evaluation of one's financial situation. Subjective measures can help account for unobserved factor (e.g., private wealth) that will shape whether an individual experiences at the same income shock as hardship or not. More information on the measurement of these variables is available in Appendix 3.1.

As latent Markov models are not very common in political science, we briefly discuss some of their key features, focusing on those most relevant for our analysis. With three latent categories, these models estimate a total of nine transition probabilities, though in practice we only focus on four (left-to-center, center-to-left, right-to-center, center-to-right). ${ }^{11}$ Given the correlation between economic attitudes

\footnotetext{
${ }^{10}$ Because political interest does not vary with economic attitudes, subsetting on political interest ensures we can fit our preferred three categories measurement model.

11 The left-to-center (right-to-center) transition rate is equal to 1 minus the left-to-left (right-to-right) transition rate.
} 
and partisanship, some transition probabilities are more common for Labour voters than for Conservative voters (and vice versa), something we will come back to when interpreting the results. Ultimately, we are most interested in people paying attention to the Labour Party's messaging. Yet, because economic preferences are highly correlated with partisanship, focusing on Labour voters only would imply a highly imbalanced dataset (469 respondents classified as right-wing against 2589 classified as left-wing). To be able to present stable results on the effects of hardship on all possible transitions rates, we run the analysis on the full sample. In Appendix 3.3, we show that our results are robust to limiting our analysis to Labour sympathizers using a measurement model adapted to the left skew in attitudes. Note that the coefficient on $w_{i t}$ measures the effects of a change in material conditions (relative to no change) on the logit of each transition probabilities. While the sign of these coefficients can be substantively interpreted, their size cannot. To get an idea of the substantive effect of hardship, we will turn to predicted values.

\section{Alternative Modeling Strategies}

When using panel data and multiple items to study attitudinal change, it is common practice to assume a continuous outcome (instead of a categorical outcome) and combine multiple survey items into an index using weights recovered from a factor analysis (Ansolabehere et al., 2008). With a continuous outcome, researchers most often rely on OLS regressions with year and individual fixed effects. As demonstrated in Appendix 5, with this empirical strategy, we can show that people who experience a change in their material circumstances from good to worse are also more likely to move from right to left on such continuous indicator. However, compared to our preferred modeling strategy, these more common specifications offer an inadequate test of our argument. Indeed, given that we are interested in estimating the effect of hardship on attitudinal stability, we need a modeling strategy that can distinguish between attitudinal persistence that is not tied to hardship on the one hand, and hardship-induced resistance on the other. This is exactly what our model does: persistence is captured by the first-order Markov transition process in which the state at time $t$ may depend on the state at time $t-1$; resistance is capture as the effect of a change in material condition on persistence. Traditional linear regression techniques are less well-suited for this purpose. ${ }^{12}$ Furthermore, our preferred model, because it models the effect of hardship separately for each transition probability, allows us to zoom in on the subset of respondents most relevant for our argument (i.e., people moving out of the consistently left-wing category). In contrast, linear models commonly used with panel data can only safely recover the effect of hardship averaged across different attitudinal "starting points.",13

\footnotetext{
${ }^{12}$ For example, in the context of an OLS regression with individual fixed effects (the gold standard when using panel data), if a given respondent does not have any variation from wave to wave, then he or she contributes nothing to the estimation.

${ }^{13}$ Indeed, with fixed effects and first differences models, introducing attitudes at time $t-1$ as an interaction term is not good practice.
} 
Table 1 Estimated mean transition probabilities of economic attitudes

\begin{tabular}{llll}
\hline & \multicolumn{2}{l}{ Econ at[t-1] } & \\
\cline { 2 - 4 } Econ at[t] & Left-wing & Centrist & Right-wing \\
\hline Proportion & 0.20 & 0.57 & 0.22 \\
Left-wing & 0.87 & 0.03 & 0.00 \\
Centrist & 0.12 & 0.94 & 0.01 \\
Right-wing & 0.00 & 0.02 & 0.99
\end{tabular}

Based on the estimation of model 1 (a) Preference Dealignment

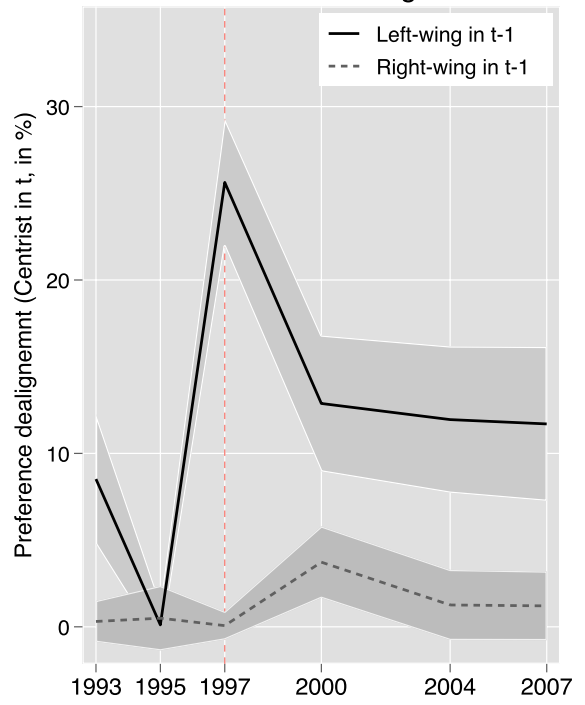

(b) Preference Realignment

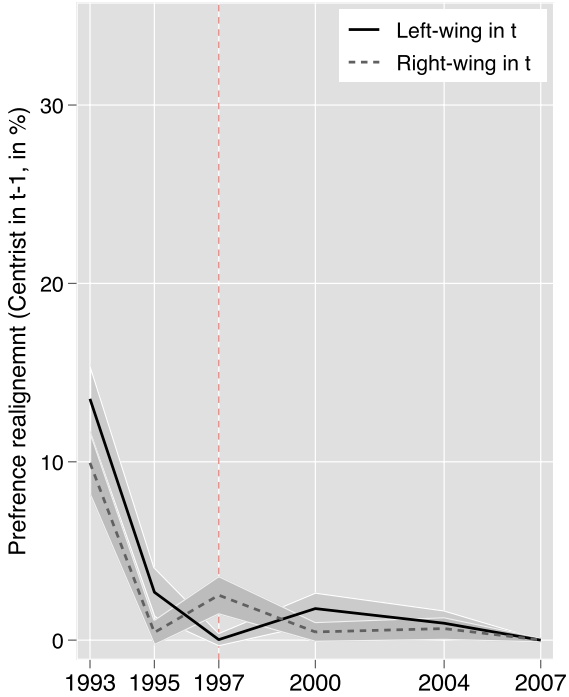

Fig. 2 Time-varying predicted probabilities of change in economic attitudes (incl. 95\% CI). Based on the estimation of model 2

\section{Results}

\section{The Dynamics of Economic Attitudes}

Table 1 shows the average share of each latent class alongside the nine average transition probabilities. Based on the latent class model, close to half of the sample can be classified as having response patterns falling on one of the two sides of the traditional economic cleavage (20\% left-wing, $22 \%$ right-wing). The other half appears ambivalent, potentially available to both sides of the debate on specific issues depending on how survey questions and issues are framed and which considerations are primed. Table 1 shows that a switch from being classified consistently left-wing to being classified consistently right-wing (or vice versa) is extremely rare. In line with prediction 1, we find evidence of a right-wing shift in response patterns: 


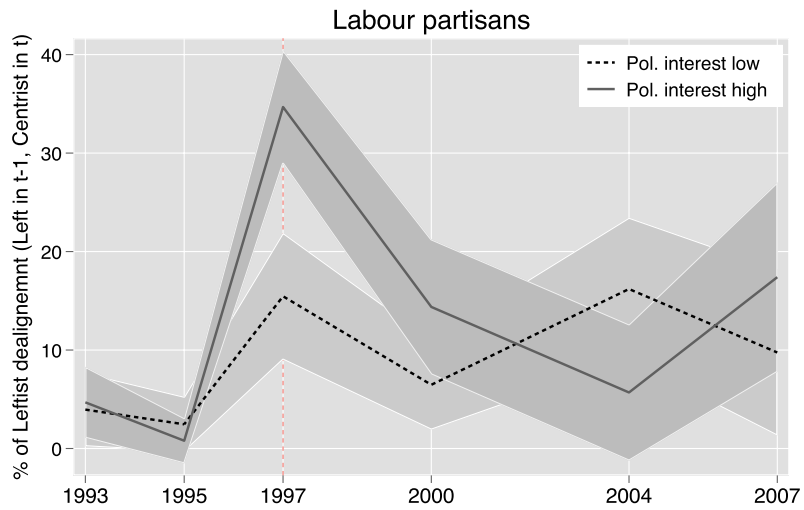

Fig. 3 Time-varying predicted probabilities of left-wing dealignment (left-wing in $t-1$; centrist in $t$ ) by political interest and partisanship (incl. 95\% CI). Based on the estimation of model 3, done separately for people below and above median political interest. Initial partisanship is measured as partisanship in the first three waves (pre-1997)

left-wing respondents' average probability of becoming centrists is 13this transition rate is averaged over the 6 transition periods available in the data. This means that by 2007, the share of left-wing respondents in the sample has declined by over 50compared to 1991.

To test the claim that most of these transitions away from left-wing patterns of answers are occurring around 1997, we allow the transition estimates to vary by year (model 2). Figure 2A plots the dynamics of attitudinal change focusing on the probability of switching from being consistently left-wing or right-wing to becoming ambivalent-centrists, something we call preference dealignment for short (i.e., neither consistently left-wing nor right-wing). Behind an average transition rate of 13reaching 26years. In contrast, we hardly see any change from right-wing to centrist economic attitudes. In other words, left-wing respondents, most of them Labour sympathizers, are experiencing attitudinal change that mirror shifts in the Labour party's rhetoric. Right-wing respondents, most of them symapthizing with the Conservative party, are staying put.

For comparison, Fig. 2B plots the proportion of ambivalent-centrist respondents who shift to more consistently left-wing or right-wing response patterns (i.e., preference realignment) from one wave to the next. Over the period, preference realignment is virtually nonexistent. To paraphrase Sniderman and Bullock (2004), it is easier for voters to be consistent when faced with supply-side dynamics that take the form of "a clash of competing arguments." When two parties converge on economic issues, the clash is no more, making it harder for ambivalent respondents to move one way or the other.

Overall, the BHPS provides support for the claim that the timing and nature of the change in elite-level competition, and its impact on the discursive context, shape aggregate attitudinal trends. In line with prediction 1, the bulk of the shift occurs in 1997 among left-wing respondents, which mirrors changes in the political discursive context. If attitudinal change, as captured in survey data, directly shapes what elites 
Table 2 Economic attitudes and changes in material conditions: coefficients from a multinomial logistic regression

\begin{tabular}{|c|c|c|c|c|}
\hline \multirow{3}{*}{$\begin{array}{l}\text { IV: Material interest } \\
\text { Lagged Latent Class (t-1) }\end{array}$} & \multicolumn{2}{|l|}{ Left-wing } & \multicolumn{2}{|l|}{ Right-wing } \\
\hline & coef. & s.e. & coef. & s.e. \\
\hline & $\sqrt{ }$ & & $\sqrt{ }$ & \\
\hline \multicolumn{5}{|c|}{ Objective material conditions } \\
\hline \multicolumn{5}{|c|}{ Unemployment (ref: employed) } \\
\hline Unemp in $\mathrm{T}$ and $\mathrm{T}-1$ & 0.250 & 0.173 & $-0.659^{* *}$ & 0.253 \\
\hline Became unemp in $\mathrm{T}$ & $0.322^{*}$ & 0.138 & -0.037 & 0.253 \\
\hline \multicolumn{5}{|c|}{ Income change (ref: no change) } \\
\hline Drop by at least $25 \%$ & $0.209^{* *}$ & 0.084 & 0.032 & 0.131 \\
\hline Increase by at least $25 \%$ & -0.058 & 0.064 & 0.119 & 0.107 \\
\hline \multicolumn{5}{|c|}{ Subjective material conditions } \\
\hline \multicolumn{5}{|l|}{ Job security (ref: no change) } \\
\hline Got worse & $0.373^{* * *}$ & 0.095 & $-0.514^{* * *}$ & 0.134 \\
\hline Got better & 0.136 & 0.091 & 0.217 & 0.182 \\
\hline \multicolumn{5}{|c|}{ Financial situation (ref: no change) } \\
\hline Worse off & $0.342^{* * *}$ & 0.081 & $-0.432^{* * *}$ & 0.117 \\
\hline Better off & 0.092 & 0.073 & -0.075 & 0.129 \\
\hline
\end{tabular}

Significance levels: ${ }^{*} p<0.05,{ }^{* *} p<0.01^{* * *} p<0.001$. The results report are based on separate multinomial logistic regressions (model 4) for each set of material interest variables. The models additionally include the lagged class position $\left(\theta_{t-1}\right)$. The corresponding timechanging coefficients $\left(\beta_{1 r s t}\right)$ are not reported here. All variables are measured as the time difference between two surveys that included the economic attitude items. $\mathrm{N}$ obs.: 5745

compete over, then this timing is surprising: we would expect most of the attitudinal change to precede Tony Blair's election, which is not the case (see Appendix 1.4 for more evidence).

Next, we examine if Labour sympathizers who are interested in politics are more likely to be among the "followers" and shift from a left-wing pattern of answers to a more ambivalent one. Figure 3 plots predicted transition rates obtained after running model 3 separately for people with high and low interest in politics. In line with expectations, Labour partisans who pay more attention to politics, mirror changes in elite discourse more closely. For this group, the probability of becoming ambivalentcentrist conditional on starting left-wing is 35\% percent between 1995 and 1997 , while only around 15respondents with low levels of political interest exhibit this pattern of change. ${ }^{14}$

\footnotetext{
${ }^{14}$ In Appendix 4, we show that, in line with prediction 1, the few Conservative voters that our model classifies as left-wing at $t-1$ are also less likely to "follow."
} 

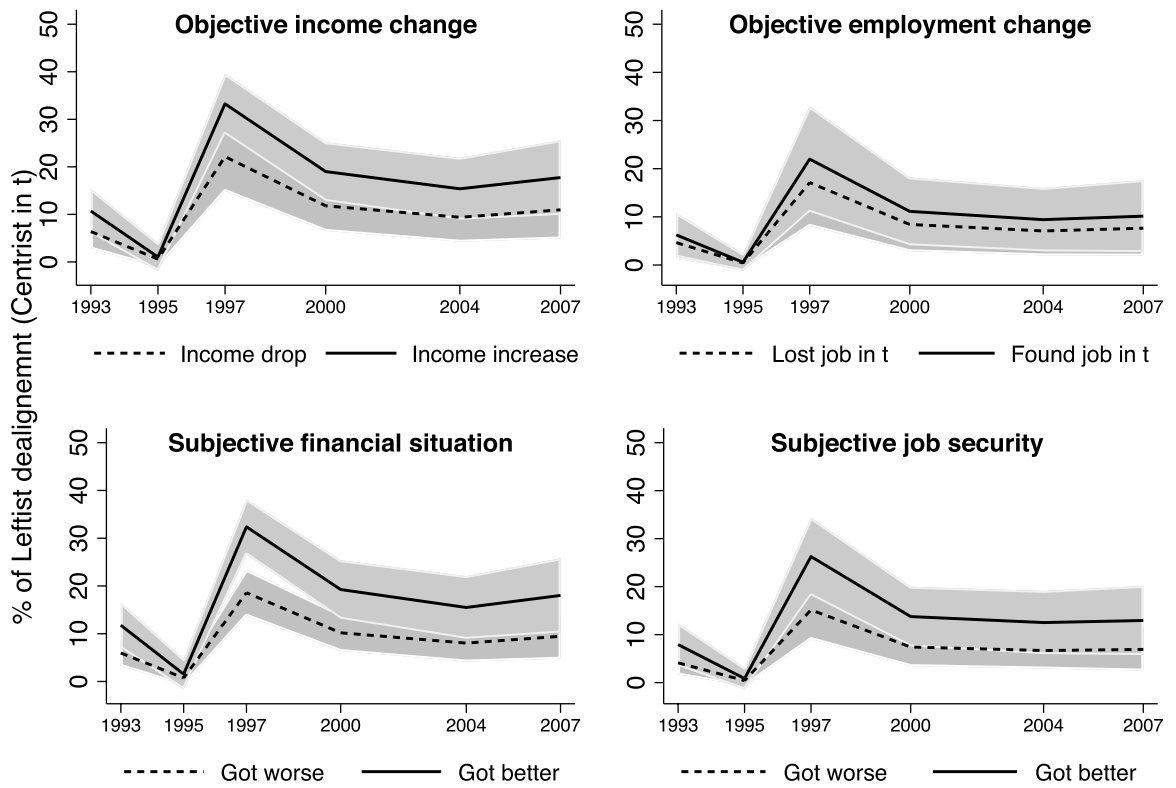

Fig. 4 Left-wing Dealignment (Left-wing in $t-1$; Centrist in $t$ ) by material interest. Based on the estimation of model 4

\section{Material Conditions and Changes in Economic Attitudes}

We now examine whether individual material conditions shape economic policy preferences in line with the resist/accept mechanism presented above. As stated with prediction 2, we expect individuals experiencing hardship to be more likely to resist transitioning away from the consistently left-wing latent class. The results testing prediction 2 are presented in Table 2 and Fig. 4. Table 2 reports the estimates of a series of multinomial logistic regression models (model 4). The ambivalent-centrist category (at time t) constitutes the reference category. ${ }^{15}$ This means that the estimates in the left-wing (right-wing) column model the probability of being leftwing (right-wing) at time $t$ relative to the probability of being an ambivalent-centrist at time $t .{ }^{16}$ Substantively, the results fit our expectations: those who experience hardship between time $t-1$ and $t$ (compared to those who have stable economic conditions) are more likely to be consistently left-wing than to be ambivalent centrists. They are also less likely to be consistently right-wing than to be ambivalent centrists.

\footnotetext{
15 Indeed, the ambivalent-centrist is the "cross-road" category, i.e., the category people experiencing attitudinal change either transition into or out of.

16 We do not report the time-varying coefficients of the lagged latent economic attitudes (the $\theta_{t-1}$ in model 1). The results are available upon request. See Fig. 4 for quantities of interest.
} 
The estimates presented in Table 2 are only a partial test of prediction 2. First, they are regression coefficients from separate multinomial logistic and do not distinguish between people who become left-wing (instead of remaining ambivalent) and people who remain left-wing (instead of becoming ambivalent). With prediction 2, we are interested in the latter group, not the former. Second, these estimates capture average effects across the whole period and do not convey the interaction between period-specific changes in elite discourse and material self-interest. To test prediction 2, we consequently compute predicted values using the estimates presented in Table 2 as well as the coefficients on the wave dummies estimated in model 4 and the coefficients on the lagged latent economic attitudes ( $\beta_{1 r s t}$, estimates not shown). In Fig. 4, we focus on predicting transition rates from left-wing to ambivalent response at different levels of hardship. Results for alternative transition rates are presented in Appendix 4 and discussed below.

As shown in Fig. 4, individuals who remain consistently left-wing on economic policy issues are also more likely to have experienced an economic shock. For examples, in 1997 individuals who have experienced no change in their perceived financial security have a transition probability of around 35individuals who experienced worsening of their financial security, this probability hovers around 15 subjective experience of economic hardship increases attitudinal persistence, net of other persistence mechanisms. We find the same result when using objective measures of hardship. ${ }^{17}$ As previously discussed, measurement error (since some people do not experience income or job loss as hardship) means that results obtained using objective measures of hardship offer a more conservative test. Ultimately, irrespective of the measure of hardship used, results align with prediction 2 .

In Appendix 4, we present predictions for transitioning in-and-out of the centrist and right-wing categories. Hardship plays a limited role given already high levels of attitudinal stability. Still, the figures show that between 1991 and 1993, people experiencing hardship had a higher likelihood of transitioning from right-wing to ambivalent-centrist. During this period, John Major was arguing for a more "caring conservatism." Our argument suggest that Conservative voters and sympathizers experiencing hardship might have been more receptive to this message. Unfortunately, due to data availability, we cannot examine this conjecture in detail.

\section{Robustness Checks}

The successful 1997 strategic repositioning of the Labour party raise two possible concerns for our analysis. One is partisan cheerleading: respondents more likely to "follow" might also be reporting improved conditions just to cast a positive light on the Labour party (Bullock \& Lenz, 2019). ${ }^{18}$ Notice, however, that effect sizes in Table 2 are much larger for people who reported a worsening of their economic

\footnotetext{
17 Note, however, that in the case of job loss, the low number of such events imply large and overlapping confidence intervals.

18 This assumes partisan cheerleading affects egocentric evaluations not just sociotropic ones. To the best of our knowledge, the existing evidence only concerns sociotropic evalutations.
} 
conditions than for people who reported an improvement. This suggests that partisan cheerleading is not driving our results: if this was the case, effect sizes should be stronger for respondents reporting improved conditions. Furthermore, partisan cheerleading implies different results depending on the measure of hardship used: positive for subjective measures, null for objective measures (given that reverse causality is highly unlikely). Yet, we document the same resistance effect across both types of measures.

Another related concern is the role of switchers, who might be Blair enthusiasts engaging in Blair-specific cheerleading. Indeed, the Labour party's strategic repositioning toward the center attracted a new type of voters: in our panel $23 \%$ of people who declared a proximity to the Labour party in 1997 had never expressed such sympathies in past waves. Still, remember that our argument and results emphasize left-wing respondents becoming more ambivalent: the overwhelming majority of switchers do not have left-wing economic preferences to start with, making it extremely unlikely that this group's enthusiasm for Blair is driving our results. ${ }^{19}$ Because we are relying on panel data, there is also no concern that compositional changes are driving our results.

We ran several additional analyses to check the robustness of our findings. As previously mentioned, we replicate the analysis presented in Table 2 on Labour sympathizers only and find similar results. We also replicate the full analysis using a continuous additive index as our outcome variable. Specifically, to test predictions 1, we use OLS regressions and include year fixed effects interacted with partisanship and political interest. To identify the unconditional effects of hardship (partial test of prediction 2), we include individual fixed effects. As shown in Appendix 5, our main results - the 1997 break, the mediating role of partisanship and political interest, and the average effect of hardship on economic attitudes-replicate no matter how we specify the models.

We also replicate our main analysis using gender attitudes as the outcome of interest instead of economic attitudes. Specifically, we investigate whether the year 1997 produced a more general change in political attitudes, no matter the issue and irrespective of a change in elite discourse. Gender issues were not politicized in the 1997 election and finding similar variations in patterns of answers to questions about gender would cast doubt on our results. As documented in Appendix 6, and in contrast to the economic policy items, we find no meaningful variations in gender attitudes over time.

\section{Discussion}

A strong assumption in American public opinion research is that changes in mass preferences in a given issue area follow from changes in whether and how elites agree or disagree over this particular issue. The findings presented in this paper

\footnotetext{
19 Out of more than 5000 observations, only 101 can be reasonably classified as both switcher and consistently left-wing on economic issues.
} 
align with these expectations. Mirroring the Labour Party's shift to the center, we find that the increase in respondents classified as ambivalent-centrists comes at the expense of people classified as economically left-wing, a majority of which identify with the Labour Party. This increase is concentrated among those who pay most attention to politics and are thus exposed to new elite messaging. Most importantly, we show that material self-interest can help distinguish between people who resist party cues on economic issues and people who accept them. We find that individuals experiencing hardship are more likely to resist considerations that do not align with their own experience of economic insecurity. While this paper examines the relationship between people's economic conditions and their preferences on economic issues, the argument easily extends to non-economic issue areas: for example, a shift in favor of gun control among Republican leaders should increase support among Republican voters, though less so among gun owners.

Scholars and commentators often ponder over what one might call the "missing left turn," i.e., the fact that trade-related economic shocks and rising inequality do not appear to benefit an egalitarian redistributive agenda (Bermeo \& Bartels, 2014). Our argument and results speak to this debate. Underpinning the latter is the expectation that adverse economic events, such as the Great Recession, will be followed by left-wing shifts in mass economic policy preferences. Based on the model tested in this paper, political economists need to take seriously the mediating role of elite competition and the discursive context, distinguishing between favorable and unfavorable supply-side dynamics. Indeed, the latter can mute (or in some conditions demultiply) the effect of economic hardship. For example, if, as it happened during the Great Recession, mainstream parties all emphasize austerity measures and spending cuts, left-wing shifts in economic attitudes are less likely to materialize. More generally, in light of long-term elite convergence on economic issues (documented in Appendix 1.2), as well as the organizational decline of institutions that target leftwing messaging to economically insecure workers (e.g., trade unions or communist parties), expectations of a left turn underpinned by a left-wing attitudinal shift are likely misplaced.

Finally, our results help explain contrasting findings on economic hardship's limited causal effect on the one hand, and its much larger predictive power in cross-sectional data on the other. Studies of attitude formation and change have routinely concluded that, on economic issue, material conditions and material self-interest plays a limited role (Margalit, 2019; O'Grady, 2019). Yet there is strong evidence that policy-relevant beliefs and preferences are not randomly distributed in the population: relative to high-income individuals, low-income individuals are more likely to find income differences unfair and more likely to support income redistribution and government provided income protection (Hvidberg et al., 2020). How to reconcile these contradictory patterns?

First, our friendly amendment to Zaller's framework suggests that material selfinterest's proverbial glass is not as empty as often assumed. Due to data availability, existing studies often focus on changes in answers to a single survey item (e.g., Margalit, 2013; O'Grady, 2019). In practice, these studies implicitly test-and rejectthe hypothesis that material self-interest can overpower mechanisms that have systematic and coordinated effects (e.g., elite rhetoric as mediated by the partisan 
heuristic) or overpower the noise generated by how people answer surveys (e.g., all the different considerations that can be primed to answer a given survey question). In this paper, we have tested a different hypothesis, namely that the observable implications of material self-interest are partly conditioned by changes in elite messaging (elites as "first movers") and by respondents' prior beliefs and attitudes (the "basket" of considerations). In the British case, one of elite convergence on economic issues, self-interest matters as a source of resistance, and consequently, as a source of attitudinal stability. Empirical strategies that fail to account for the latter risk under-estimating the effect of a change in economic conditions.

Second, our results indicate that economic attitudes form at the intersection between the discursive context and individual material conditions. Building on the theoretical framework described in this paper, we can conjecture that a strong correlation between individual socio-economic conditions and attitudes emerges at times when redistribution and social insurance are highly politicized and constitute a salient political cleavage. In this case, elite messaging, the partisan heuristic and material self-interest reinforce each other to generate economic attitudes that covary with differences in economic experiences. Where this correlation exists, it is likely a legacy of previous episodes of class-based mobilization.

Supplementary Information The online version contains supplementary material available at https://doi. org/10.1007/s11109-021-09768-w.

Open Access This article is licensed under a Creative Commons Attribution 4.0 International License, which permits use, sharing, adaptation, distribution and reproduction in any medium or format, as long as you give appropriate credit to the original author(s) and the source, provide a link to the Creative Commons licence, and indicate if changes were made. The images or other third party material in this article are included in the article's Creative Commons licence, unless indicated otherwise in a credit line to the material. If material is not included in the article's Creative Commons licence and your intended use is not permitted by statutory regulation or exceeds the permitted use, you will need to obtain permission directly from the copyright holder. To view a copy of this licence, visit http://creativecommons.org/licen ses/by/4.0/.

\section{References}

Ansolabehere, S., Rodden, J., \& Snyder, J. M. (2008). The strength of issues: Using multiple measures to Gauge preference stability, ideological constraint, and issue voting. American Political Science Review, 102(02), 215-232.

Bermeo, N. \& Bartels, L. M. (2014). Oxford University Press, pp. 1-39.

Boninger, D. S., Krosnick, J. A., \& Berent, M. K. (1995). Origins of attitude importance: Self-interest, social identification, and value relevance. Journal of Personality and Social Psychology, 68(1), 61.

Broockman, D. E. (2016). Approaches to studying policy representation. Legislative Studies Quarterly, 41(1), 181-215.

Brooks, C., \& Svallfors, S. (2010). Why does class matter? Policy attitudes, mechanisms, and the case of the Nordic countries. Research in Social Stratification and Mobility, 28(2), 199-213.

Bullock, J., \& Lenz, G. (2019). Partisan bias in surveys. Annual Review of Political Science, 22, 325-342.

Carsey, T. M., \& Layman, G. C. (2006). Changing sides or changing minds? Party identification and policy preferences in the American electorate. American Journal of Political Science, 50(2), 464-477.

Cavaille, C., \& Trump, K.-S. (2015). The two facets of social policy preferences. Journal of Politics, 77(1), 146-160. 
Chan, T. W., \& Goldthorpe, J. H. (2007). Class and status: The conceptual distinction and its empirical relevance. American Sociological Review, 72(4), 512-532.

Chong, D., Citrin, J., \& Conley, P. (2001). When self-interest matters. Political Psychology, 22(3), 541-570.

Dancey, L., \& Goren, P. (2010). Party identification, issue attitudes, and the dynamics of political debate. American Journal of Political Science, 54(3), 686-699.

DeScioli, P., \& Kurzban, R. (2009). Mysteries of morality. Cognition, 112(2), 281-299.

Evans, G., \& Tilley, J. (2012). How parties shape class politics. British Journal of Political Science, 42(1), 137-161.

Fielding, S. (2003). The labour party: Continuity and change in the making of 'New' labour. Palgrave Macmillan.

Heath, O. (2018). Policy alienation, social alienation and working-class Abstention in Britain, 19642010. British Journal of Political Science, 48(4), 1053-1073.

Howe, L., \& Krosnick, J. (2017). Attitude strength. Annual Review of Psychology, 68, 327-351.

Hvidberg, K. B., Kreiner, C., \& Stantcheva, S. (2020). Social position and fairness views. Technical Report, National Bureau of Economic Research, WP28099.

Krosnick, J. A., Boninger, D. S., Chuang, Y. C., Berent, M. K., \& Carnot, C. G. (1993). Attitude strength: One construct or many related constructs? Journal of Personality and Social Psychology, 65(6), 1132.

Langsæther, P. E., \& Evans, G. (2020). More than self-interest: Why different classes have different attitudes to income inequality. The British Journal of Sociology, 71(4), 594-607.

Leeper, T. J., \& Slothuus, R. (2014). Political parties, motivated reasoning, and public opinion formation. Political Psychology, 35(S1), 129-156.

Lenz, G. S. (2013). Follow the leader? How voters respond to politicians' policies and performance. University of Chicago Press.

Margalit, Y. (2013). Explaining social policy preferences: Evidence from the great recession. American Political Science Review, 107(01), 80-103.

Margalit, Y. (2019). Political responses to economic shocks. Annual Review of Political Science, 22, $277-295$.

Marshall, J. (2016). Education and voting conservative: Evidence from a major schooling reform in Great Britain. The Journal of Politics, 78(2), 382-395.

Milazzo, C., Adams, J., \& Green, J. (2012). Are voter decision rules endogenous to parties' policy strategies? The Journal of Politics, 74(01), 262-276.

Montada, L. (1998). Belief in a just world: A hybrid of justice motive and self-interest? In J. Maes (Ed.), Responses to victimizations and belief in a just world (pp. 217-246). Springer.

Neundorf, A., \& Cavaille, C. (2021). Replication data for: Elite cues and economic policy attitudes: The mediating role of economic hardship. Technical Report v1, Harvard Dataverse. https://doi.org/10. 7910/DVN/TY8RB9

Neundorf, A., Stegmueller, D., \& Scotto, T. J. (2011). the individual level dynamics of bounded partisanship. Public Opinion Quarterly, 75(3), 458-482.

O'Grady, T. (2021). The transformation of British welfare policy: Politics, discourse and public opinion. Oxford University Press.

O'Grady, T. (2019). How do economic circumstances determine preferences? Evidence from long-run panel data. British Journal of Political Science, 49(4), 1381-1406.

Prior, M. (2010). You've either got it or you don't? The stability of political interest over the life cycle. The Journal of Politics, 72(3), 747-766.

Rodden, J. A. (2019). Why cities lose: The deep roots of the urban-rural political divide. Basic Books.

Sears, D. O., \& Funk, C. L. (1991). The role of self-interest in social and political attitudes. Advances in Experimental Social Psychology, 24(1), 1-91.

Sears, D. O., \& Funk, C. L. (1990). The limited effect of economic self-interest on the political attitudes of the mass public. Journal of Behavioral Economics, 19(3), 247-271.

Sniderman, P. M., \& Bullock, J. (2004). A consistency theory of public opinion and political choice: The hypothesis of menu dependence. In W. E. Saris \& P. M. Sniderman (Eds.), Studies in public opinion (pp. 337-357). Princeton University Press.

Volkens, A., Lehmann, P., Merz, N., Regel, S., Werner, A., Lacewell, O., \& Schultze, H. (2013). The Manifesto Data Collection. Manifesto Project (MRG/CMP/MARPOR). https://manifesto-project. wzb.eu 
Zaller, J., \& Feldman, S. (1992). A simple theory of the survey response. American Journal of Political Science, 36(3), 579-616.

Zaller, J. R. (1992). The nature and origins of mass opinion. Cambridge University Press.

Zaller, J. R. (2013). What nature and origins leaves out. Critical Review, 24(4), 569-642.

Publisher's Note Springer Nature remains neutral with regard to jurisdictional claims in published maps and institutional affiliations.

\section{Authors and Affiliations}

\section{Charlotte Cavaillé ${ }^{1}$ Anja Neundorf ${ }^{2}[$}

Charlotte Cavaillé

cavaille@umich.edu

1 Ford School, University of Michigan, Ann Arbor, USA

2 School of Social and Political Sciences University of Glasgow, Glasgow, UK 